\title{
A HIGH SENSITIVE MICROWAVE MEASURING DEVICE OF THE MOISTURE CONTENT IN THE NON-POLAR DIELECTRIC LIQUIDS BASED ON AN INHOMOGENEOUS STEP COAXIAL RESONATOR
}

\begin{abstract}
Purpose. Objective is to create a moisture meter for non-polar liquid dielectrics with low volumetric moisture content of more than $10^{-3} \%$. Methodology. Moisture measuring is based on dielcometric method. It is implemented as a resonant method of determining a capacitance measuring transducer. Measuring transducer capacitive type has a working and parasitic capacitance. It was suggested the definition of moisture on four of resonance frequencies: when the measuring transducer is turned off, one by one filled with air, "dry" and investigated liquid, to determine the parasitic capacitance of the measuring generator, and the parasitic capacitance of the measuring transducer and humidity. Measurement frequency was increased up to microwave range to increase the sensitivity. Measuring transducer with distributed parameters representing a step heterogeneous coaxial resonator is used by. This measuring transducer has a zero stray capacitance, because the potential electrode has a galvanic connection with an external coaxial electrode. Inductive ties loop is used to neglect parasitic capacitance of the measuring generator, and to increase the quality factor of the system. Measuring moisture is reduced to measuring the two frequencies of resonance frequency and "dry" and investigated liquid. Resonant characteristics transducer in a step inhomogeneous coaxial resonator have been investigated to determine the quality factor of filled with air and transformer oil, and experiments to measure the moisture content in transformer oil have been conducted. Results. Measuring transducer of distributed type is developed and researchedit is step inhomogeneous coaxial resonator. It has a smaller geometric length and larger scatter of the first and second resonant frequencies. Expression is obtained for determination of moisture on the basis of two resonant frequencies. The formula of the two frequencies to determine the moisture is correct. Resonant characteristics are obtained for measuring transducer. Its quality factor has been determined - it does not depend on what it is filled with air or oil. The moisture content in transformer oil for the amount of water to $10^{-3} \%$ with an error of no more than $6.7 \%$ has been determined. Originality. It has been proposed to use of an inhomogeneous step coaxial resonator as a measuring transducer. Original high sensitive moisture meter for the fluid at rest and flowing fluid with low values of parasitic capacitances has been developed and researched. An original method of determining the moisture by measuring the two frequencies of resonance has been proposed and implemented. Practical value. This meter may be used to determine moisture in any of the non-polar liquid with high speed and accuracy. Moisture meter can be used in electrical engineering, aeronautical engineering, in the chemical and food industries. References 6 , tables 1 , figures 8 . Key words: moisture meter, non-polar liquid dielectrics, measuring transducer, step inhomogeneous coaxial resonator, measuring generator, resonance characteristics, volumetric water content, transformer oil, water.
\end{abstract}

Рассматривается высокочувствительный измеритель влагосодержания в неполярных жедких диэлектриках. Аргументированы пути повышения чувствительности классического диэлькометрического метода. Приводиться описание разработанной конструкции измерителя влажсности на основе ступенчатого неоднородного коаксиального резонатора. Рассмотрены результаты анализа резонансных характеристик измерительного преобразователя, а также определены величины объемного влагосодержания смесей трансформаторное масло - вода в диапазоне влагосодержсания $\left(10-10^{4}\right) \mathrm{cm}^{3} / \mathrm{s}^{3}$. Библ. 6 , табл. 1 , рис. 8 .

Ключевые слова: измеритель влагосодержания, жидкие неполярные диэлектрики, измерительный преобразователь ступенчатый коаксиальный неоднородный резонатор, измерительный генератор, резонасные характеристики, объемное влагосодержание, трансформаторное масло, вода.

Introduction. Measuring the moisture content of the nonpolar liquid dielectrics is important for many practical applications, such as: electrical engineering, chemical industry, food industry, in the military and aviation equipment. So, for the electrical equipment is important to determine the moisture content of transformer oil, chemical and food industry - determination of moisture content in a variety of mineral oils, for the military and aviation equipment - determination of moisture content in diesel, aviation fuel. In most of the areas studied fluid (transformer and sunflower oils, diesel and jet fuel, etc.) are nonpolar liquid dielectrics.

It should be noted that the lower limit of the moisture content measurements in all of these applications is very low: the minimum value of the measured volumetric water content is not more than $10^{-3} \%$ which creates difficulties for conventional measurements of these known methods. Traditional methods such as Karl-Fischer method and liquid- chromatographic method requires special equipment rather expensive consumables and quite a long time.

The goal of the work is development of a meter moisture content in non-polar liquid dielectrics with a lower limit of volumetric water content not more than $10^{-3} \%$ allowing to quickly perform measurements with a minimum of material and time costs.

Substantiation of ways to solve the defined problem. To solve this problem dielcometric method of measuring the moisture content was chosen based on the moisture content depending on the dielectric constant study watered nonpolar liquid dielectrics [1]. The measured dielectric constant which is proportional to moisture content, characterizes the water content value itself.

To the improvement of this method in [2] a simplified model of the emulsion «water - non-polar dielectric» is proposed that allowed simply to determine 
the amount of volumetric water content in the mixture $\mathrm{W}$ as a function of dielectric permittivity $\varepsilon_{2}$ mixture and dehydrated nonpolar liquid $\varepsilon_{1}$ in the following form:

$$
W=\frac{\varepsilon_{2}-\varepsilon_{1}}{3 \cdot \varepsilon_{1}}
$$

In [3] it is proposed the use of the resonance method for determining dielectric permittivities $\varepsilon_{1} \quad$ и $\quad \varepsilon_{2}$ implemented for the measuring transducer (MT) of the capacitive type, to be filled successively and dehydrated liquid test mixture (emulsion). Thus MT connected to the capacitive measuring generator (MG) contains the amplification circuit and the feedback coil [3]. Unknown values $\varepsilon_{1}$ and $\varepsilon_{2}$ are expressed in four frequency values MG generation (frequency of MG with disconnected MT, frequency of MG with MT filled with air, frequency of the MG with MT filled with dehydrated test liquid, and frequency of the MG with MT filled with test mixture), and the values of design parameters of MT. This approach allowed in the MG frequency range from $100 \mathrm{kHz}$ to $2 \mathrm{MHz}$ practically solve the problem of determining the moisture content of the non-polar dielectrics in the range of $0.1 \% \leq W \leq 10 \%$. However, using at this approach of MG and MT systems in the form of lumped elements (a coil for the IG and a measuring capacitor for MT) which had the parasitic parameters are not allowed to fully realize the potential of the resonance dielcometry to measure extremely low levels of moisture content [3].

The analysis shows that the main directions of improving the sensitivity of the proposed in [3] dielcometry resonance method are as follows: increase in operating frequency of measurement, minimizing the parasitic capacitance of the inductive element of the $\mathrm{MG}$ and MT, increased frequency stability of MG generation in all four modes, the maximum reduction in the number of measured frequencies.

For the implementation of indicated directions by the authors MT with distributed parameters has been proposed as a step inhomogeneous coaxial resonator (SICR) [4]. Here, SICR resonance spectra were investigated in the frequency range up to $1.8 \mathrm{GHz}$. As a result of investigations carried out in [4] significant advantages of MT performed as SICR have revealed as compared to a MT with lumped parameter and compared with known MT of microwave range as quarter-wave homogeneous resonators.

Further development of the theory of SICR application in resonant dielcometry of nonpolar liquid media was developed in [5] which held as a mathematical analysis of electromagnetic processes in SICR and their simulation in Micro Cap environment. The result of these studies was to optimize for SICR for dielcometric goals and the definition of its metrological characteristics. Based on the above, the following methodology for the design of the meter was adopted:

1. The moisture content of the mixture is determined by the difference of the dielectric permittivities of the dehydrated liquid and mixture.
2. To determine the dielectric permittivities IT as SICR is connected to and alternately filled by dehydrated liquid and mixture.

3. The operating frequency of $\mathrm{MG}$ is selected as maximal possible taking into account the frequency dispersion of the dielectric permittivity of water.

4. SICR and MG have minimum values of parasitic parameters, which reduces the number of frequency measurements from four to two and reduce the experimental time by 2 times.

5. In order to improve the stability of the frequency generated by the MG, the MT is designed as a system with distributed parameters: SICR which has a substantially higher $Q$ than the lumped system «MT - MG».

Description of the meter. A flowchart of the meter is shown in Fig. 1. Used MT converter, in the form of SICR, is connected to the MG. The MG frequency generation is measured by a frequency meter $\mathrm{F}$, and the temperature of the MT - by an electronic thermometer T.

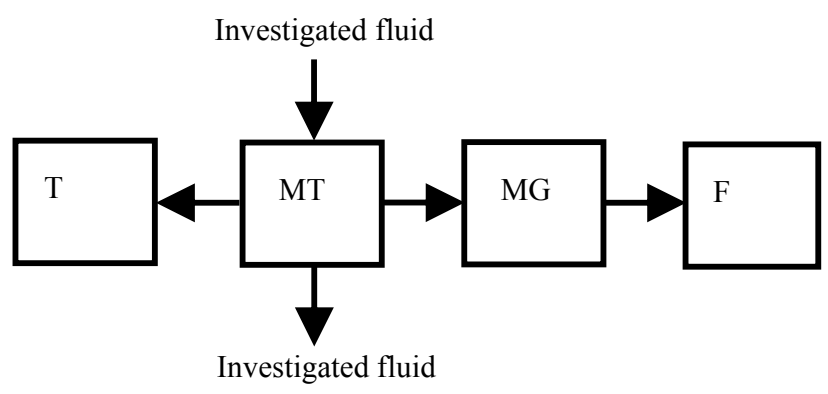

Fig. 1. Flowchart of the meter

Schematic diagram of the meter (MT together with $M G)$ is shown in Fig. 2. Its MT transducer as SICR formed as two coaxial lines $Z 1$ and $Z 2$ of equal length with different wave impedances $Z_{1}=77.61 \Omega, Z_{2}=4.09$ $\Omega$. Using inductive loop of communication $A$ transmitter is connected to the MG on the transistors Q1, Q2 which are collected by the scheme "common base» (at the MG output) - «common collector» (at the MG input).

This circuit solution of $M G$ is selected to minimize the effect of parasitic MG parameters on the parameters of MT (cascade with «common base» has a maximum output impedance and cascade with «common collector» has maximum input impedance). The signal from the emitter follower transistor Q2 is input (emitter) of the amplifying stage transistor Q1 on, the output of which is connected to the MT communication via an inductive loop $A$. The output of the $\mathrm{MG}$ through «isolation» amplifier transistor Q3 is input to a digital frequency divider U3, which is included under the scheme divider into 80 . The output of the frequency divider through a «decoupling» emitter follower transistor Q4 signal is fed to a frequency. For maximum stability, it MG frequency generating stages (Q1 - Q3) and digital stages (U3, Q4) are fed from different linear regulators U1 (9) and U2 (5 $\mathrm{V})$ voltage, respectively. 


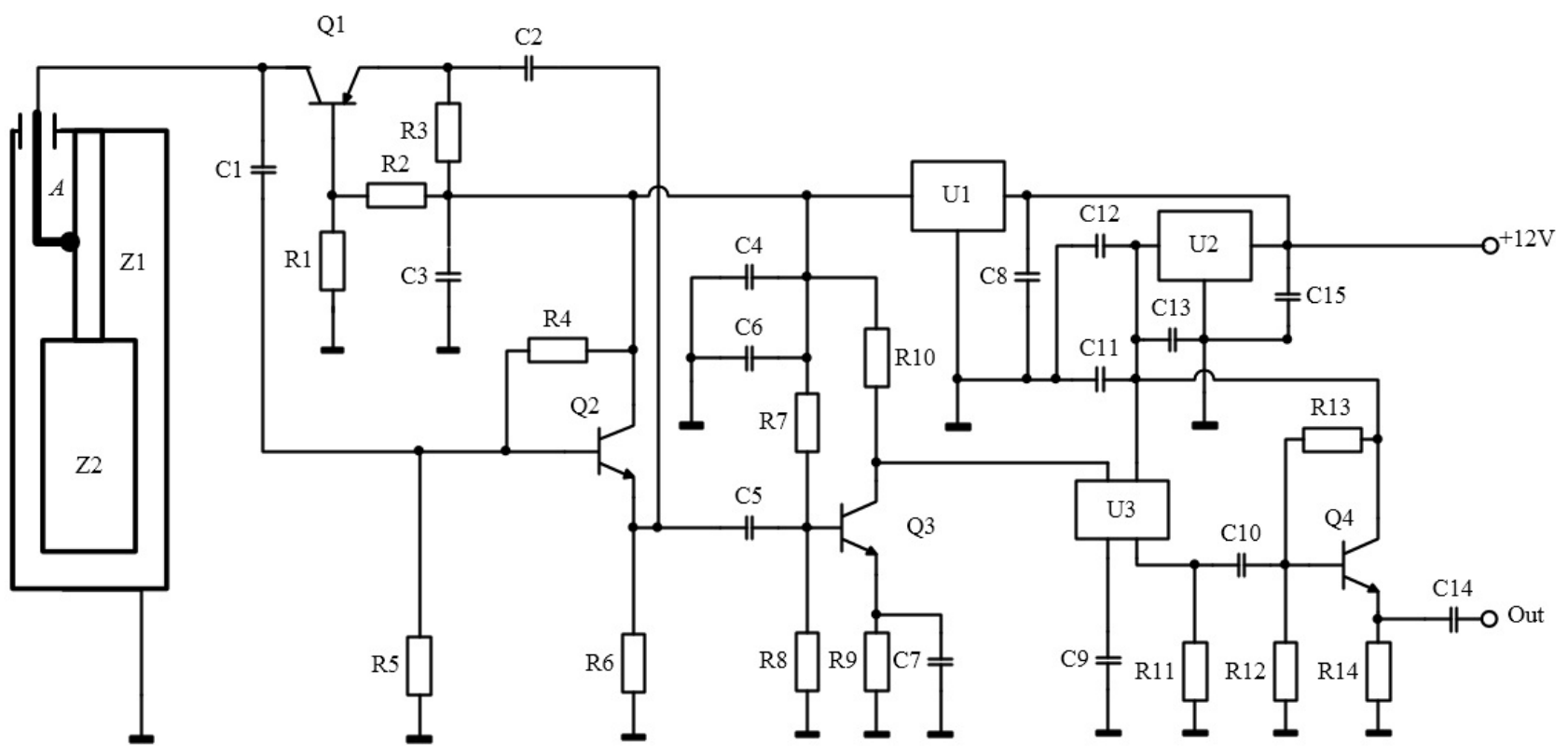

Fig. 2. Schematic diagram of the meter (MT together with MG)

Structurally, MT together with MG is a collapsible system, the bottom of which is MT and at the top - MG. In the lower part of the MT test liquid is supplied which after filling its entire volume goes to the drain. General view and the view with the cover removed measuring moisture content is shown in Fig. 3. In this constructive execution of MT and MG the MT operation is possible both in stationary mode and a test liquid flow mode. Furthermore, this design provides the IG minimize the effects of parasitic resonance frequency parameters to MT (which is determined by the geometrical dimensions of the lines $\mathrm{Z} 1$ and $\mathrm{Z} 2$ and the magnitude of test liquid dielectric constant) due to the following factors:

1 . The values of the coupling coefficient of the equivalent oscillating circuit formed by lines $\mathrm{Z} 1$ (inductive element) and Z2 (capacitive element) with MT does not exceed 0.08 . Therefore, the parasitic parameters of the IG, the MG which "are introduced» in the loop, do not exceed in magnitude $(0,08)^{2}=0.0064$. In combination with high input impedance values (for Q2) and output (for Q1) is part of an IG ensures high quality of the oscillatory system and a small influence on the frequency of the MG meter generation.

2. Place of the connection of inductive loops A, as close as possible to the point of the oscillating system, which has zero potential. This fact provides a minimum distortion of the longitudinal electric field in SICR.

3. Mechanical fixation of the central electrode line Z1, the value of parasitic capacitance provides MT is almost zero, which also helps improve the accuracy of the proposed measuring moisture content.

The described meter has the following main characteristics:

1. The frequency generation of MG with MT filled with air, about $158 \mathrm{MHz}$.

2. The frequency generation of $\mathrm{MG}$ with $\mathrm{MT}$ filled with transformer oil, about $104 \mathrm{MHz}$.

3 . The sensitivity of the meter - no worse than $1 \mathrm{~cm}^{3} / \mathrm{m}^{3}$.

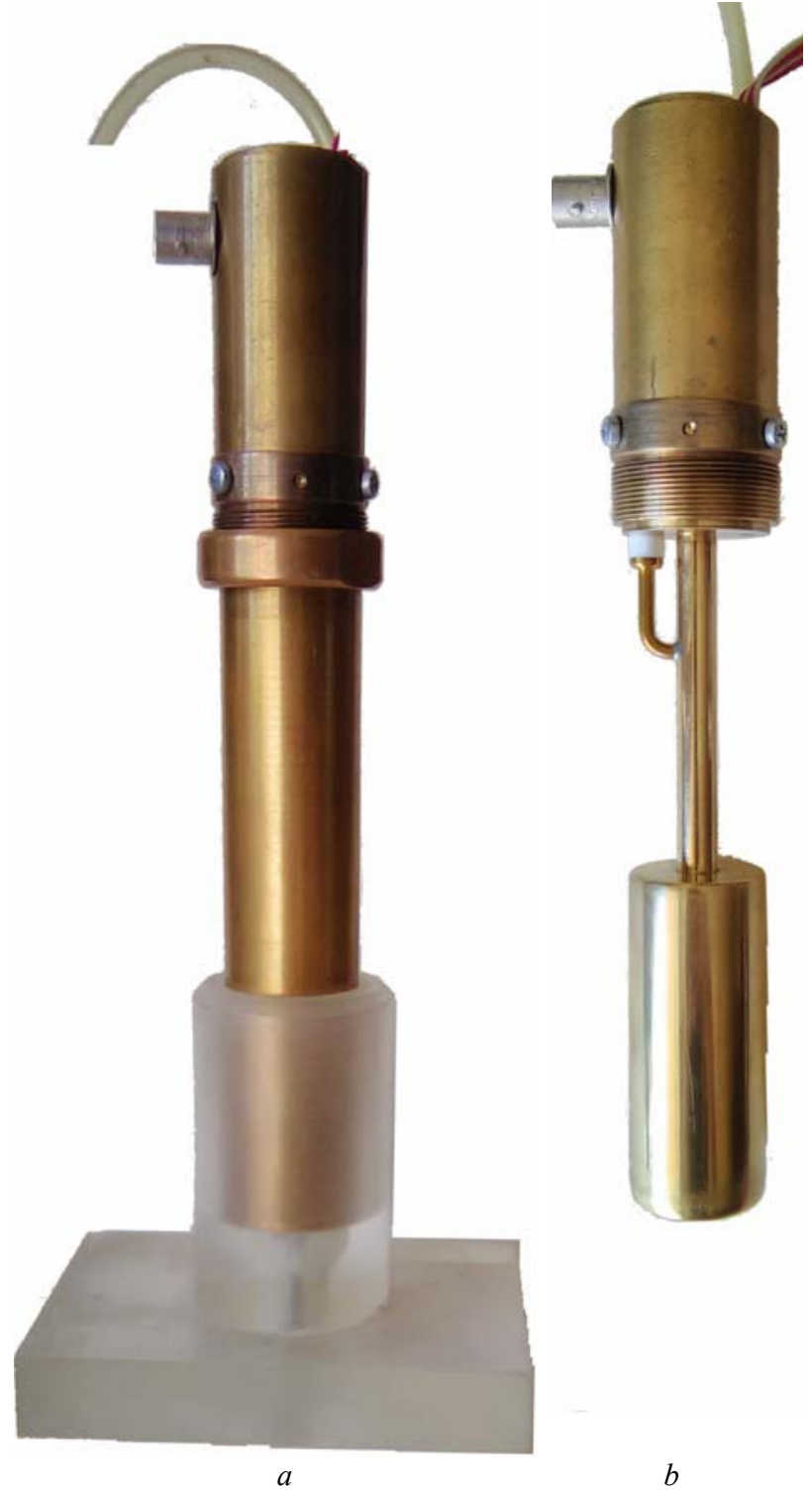

Fig. 3. General view of the assembled meter of the moisture content $(a)$ and view with removed coaxial outer electrode $(b)$ 
Results of experimental investigations. To confirm the correctness of the chosen design and technical solutions of the MG and MT pilot studies were carried out in two stages.

In the first stage using the meter amplitudefrequency characteristics (AFC) of the type X1 - 42 studied the resonance characteristics of IT filled with air, and IT filled with dehydrated transformer oil.

The block diagram on which the moisture meter investigated to determine the AFC is shown in Fig. 4.

Fig. 4 shows: $1-42$ meter AFC X1 (at the top measuring part; at the bottom - generating part); 2 - IT; 3 - Inductive loop; 4 - the medium under study; 5 - highresistance (external) input X1 - 42; 6 - output X1 - 42 $(50 \Omega)$.

Here, for removing reaction the meter X1 - 42 in the AFC output X1 SP - 42 was agreed by $50 \Omega$ resistor, and to increase the input impedance a series with the input the $100 \mathrm{k} \Omega-0.5 \mathrm{pF}$ chain was included.

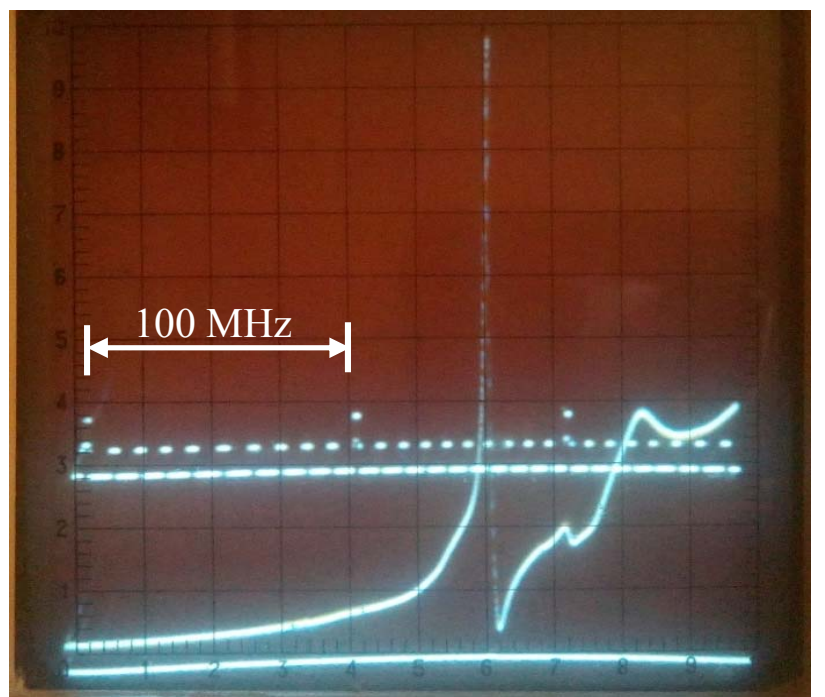

Fig. 5. Amplitude-frequency characteristics of MT filled by air

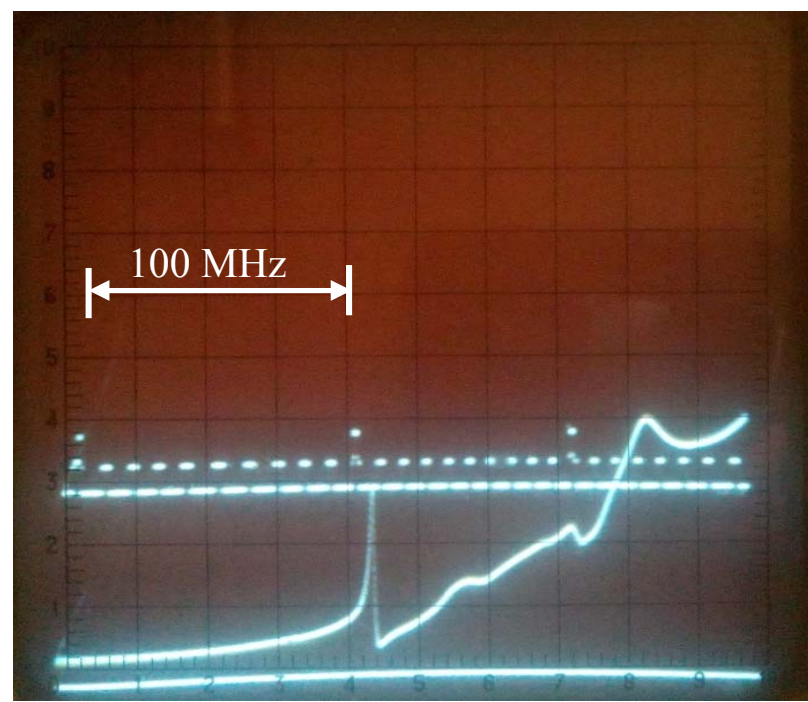

Fig. 7. Amplitude-frequency characteristics of MT filled by oil

As the results of processing with accuracy up to $5 \%$ loaded $Q$ value of MT with air $\left(Q_{1}, F_{1}\right)$ and with transformer oil $\left(Q_{2}, F_{2}\right)$ are practically the same indicating a weak influence of oil on $Q$ of MT:

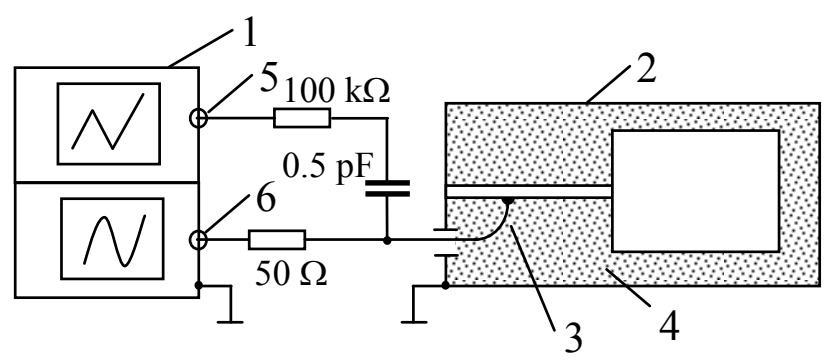

Fig. 4. Block diagram for MT AFC measurements

Results of IT investigations as MT AFC are shown in Fig. 5-8. The resulting AFC have been deciphered for the purpose of determining the value of the loaded $\mathrm{Q}$ of the measuring transducer. Loaded $Q$ (MT is loaded on $50 \Omega$ ) is determined using $2 \Delta F$ value (AFC width at $3 \mathrm{~dB}$ ) and $F$ (central resonance frequency).

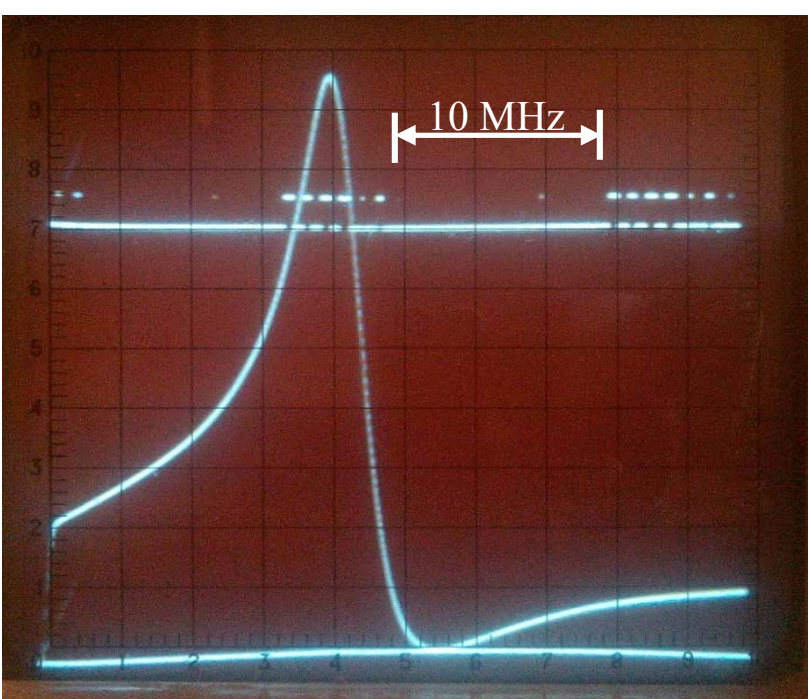

Fig. 6. Amplitude-frequency characteristics of MT filled by air

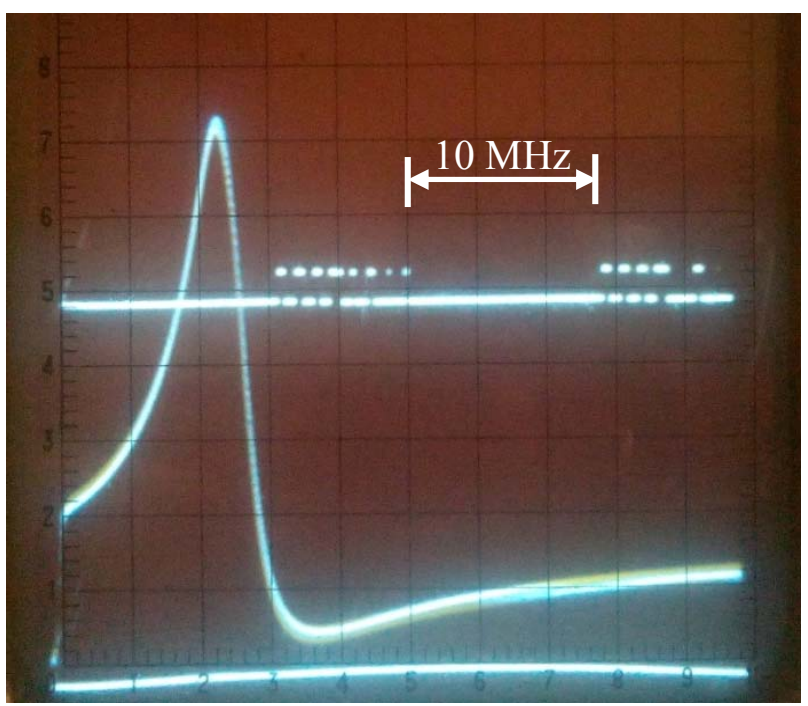

Fig. 8. Amplitude-frequency characteristics of MT filled by oil

$$
Q_{1}=\frac{F_{1}}{2 \Delta F_{1}}=\frac{160 \cdot 10^{6}}{2 \cdot 10^{6}}=80
$$




$$
\begin{aligned}
Q_{2}=\frac{F_{2}}{2 \Delta F_{2}} & =\frac{108 \cdot 10^{6}}{1,3 \cdot 10^{6}}=83 ; \\
Q_{1} & \cong Q_{2} .
\end{aligned}
$$

In the second stage of the experimental studies were identified value of volumetric moisture content of the prepared mixtures «transformer oil - water» in the moisture content range $\left(10-10^{4}\right) \mathrm{cm}^{3} / \mathrm{m}^{3}$. In the course of experiments with micro-stamps «Hamilton» in predehydrated oil of volume $(500 \pm 0.6) \mathrm{cm}^{3}$ was injected the required amount of water. Thereafter, the homogeneous emulsion was prepared with the desired moisture content.

Then, to remove gas from the non-moistured transformer oil and emulsions prepared with these vessels were placed in a vacuum chamber. After that, through the transmitter shed investigated liquid at controlling the temperature MT and the MG frequency generation is flowed. In the process of research and $\mathrm{MT}$ and $\mathrm{MG}$ temperature is kept constant with an accuracy of $\pm 0.03{ }^{\circ} \mathrm{C}$. Thus, 12 measurements are carried out by the frequency generation $\mathrm{MG}$ are divided into 80 for dewatered oils $\left(F_{3}\right)$ and the test mixture $\left(F_{4}\right)$ and are processed by standard methods for direct measurement of [6].

To determine the functional dependence of the water content $W$ on the frequency we use the formula for determining the moisture content of the moisture meter as described in [3]:

$$
W=\frac{1}{3} \cdot \frac{\frac{1}{F_{4}^{2}}-\frac{1}{F_{3}^{2}}}{\frac{1}{F_{3}^{2}}-\frac{1}{F_{1}^{2}}},
$$

where $F_{1}$ is the resonance frequency at switched off MT; $F_{3}$ is the resonance frequency for MT filled with dehydrated oil; $F_{4}$ is the resonance frequency at MT filled with considered mixture.

The design of the proposed moisture meter based on SICR is such that it does not contain a structural dielectric material supporting the inner electrode potential. Structurally, the inner electrode potential tightly connected to the outer electrode and the test liquid is in the space between the electrodes. In this case, the transducer structure may be represented as a shortcircuited quarter-wave line. Then moisture meter based on SICR has frequency $F_{1}=\infty$, and $1 / F_{1}=0$ and the expression (2) is converted to the form:

$$
W=\frac{1}{3} \cdot \frac{\frac{1}{F_{4}^{2}}-\frac{1}{F_{3}^{2}}}{\frac{1}{F_{3}^{2}}}=\frac{1}{3} \cdot \frac{F_{3}^{2}-F_{4}^{2}}{F_{4}^{2}} .
$$

For small values of the moisture $W$ content when the inequality holds is correct:

$$
\frac{F_{3}^{2}-F_{4}^{2}}{F_{4}{ }^{2}}<0,1,
$$

formula (3) for the moisture content is simplified:

$$
W \approx \frac{2}{3} \cdot \frac{F_{3}-F_{4}}{F_{4}} .
$$

The results of the moisture content of treated experimental values $W, W_{0}$ and frequencies $F_{3}, F_{4}$ are shown in Table 1.

Table 1

Treated results of measurements

\begin{tabular}{|c|c|c|c|c|}
\hline \multirow{2}{*}{$W_{0}, \mathrm{~cm}^{3} / \mathrm{m}^{3}$} & \multicolumn{2}{|c|}{ Frequency, $\mathrm{Hz}$} & \multirow{2}{*}{$W, \mathrm{~cm}^{3} / \mathrm{m}^{3}$} & $\begin{array}{c}\text { Relative } \\
\text { error, } \%\end{array}$ \\
\hline $10 \pm 1$ & $1335497.4 \pm 0.6$ & $1335478.3 \pm 0.8$ & $9.51 \pm 0.5$ & 5.2 \\
\hline $50 \pm 1$ & $1335558.1 \pm 0.6$ & $1335459.8 \pm 0.6$ & $49 \pm 0.4$ & 1.9 \\
\hline $100 \pm 5.1$ & $1304712.0 \pm 0.7$ & $1304519.7 \pm 0.8$ & $98.3 \pm 0.6$ & 1.8 \\
\hline $499 \pm 5.6$ & $1335558.1 \pm 0.6$ & $1334602.2 \pm 1.3$ & $477.7 \pm 0.7$ & 4.6 \\
\hline $999 \pm 11.2$ & $1304658.8 \pm 0.7$ & $1302569.9 \pm 1.2$ & $1069.9 \pm 0.7$ & 6.7 \\
\hline $9901 \pm 111.8$ & $1304658.8 \pm 0.7$ & $1286722.6 \pm 34.4$ & $9357.7 \pm 18.4$ & 5.8 \\
\hline
\end{tabular}

Thus, when the concentration of moisture in the prepared emulsion $W_{0}=10 \mathrm{~cm}^{3} / \mathrm{m}^{3}$ the measured value of the moisture content is $W=9.51 \mathrm{~cm}^{3} / \mathrm{m}^{3}$ and the value of $\Delta W= \pm 0.5 \mathrm{~cm}^{3} / \mathrm{m}^{3}$ that enables measurement of moisture content in the range $10^{-3} \%<W<0.1 \%$ with a relative error (defined as the difference in moisture content of the emulsion prepared and measured divided by the moisture content of the cooked) is not more than $5.2 \%$.

Analysis of the experimental results shows that the created meter is characterized at determining the moisture content by a relative error less than $6.7 \%$ in the range 10 $\mathrm{cm}^{3} / \mathrm{m}^{3} \leq W \leq 10^{5} \mathrm{~cm}^{3} / \mathrm{m}^{3}$.

\section{Conclusions.}

1. For the development of the dielcometric method for determining the moisture content in nonpolar liquid dielectrics a microwave meter the moisture content with a measuring transmitter as a step inhomogeneous coaxial resonator operating in resonant mode is developed.

2 . The correctness of the proposed for implementation of the meter the moisture content the simplified physical model of emulsion «water in oil» type is experimentally confirmed.

3. A moisture meter on the basis of an inhomogeneous step coaxial resonator which has higher frequency stability, lower parasitic parameters and higher operating frequency greater compared with a measuring instrument on the basis of a capacitive transducer and a measuring lumped generator is developed.

4. The proposed meter design allows to determine the moisture content of the test fluid at rest, and in the stream.

5. The designed meter of moisture content allows at minimum of material and time costs quickly determine the moisture content in the range of $10^{-3} \%<W<0.1 \%$ by using measurement of two resonant frequencies of the measuring transmitter (with MT filled with dehydrated oil and with MT filled with the test emulsion) and calculation of moisture content by formula [5].

\section{REFERENCES}

1. Melkumyan V.E. Izmerenie $i$ kontrol vlazhnosti materialov. [Measurement and control of humidity of materials.]. Moscow, 
Komitet standartov mer i izmeritelnyih priborov pri Sovete Ministrov SSSR Publ., 1970. 138 p. (Rus).

2. Rudakov V.V., Korobko A.I., Korobko A.A. Electrophysical model of behavior emulsion mineral oil - water engineering type. Bulletin of NTU «KhPI», 2009, no.39, pp. 158-161. (Rus). 3. Rudakov V.V. Korobko A.A. Increasing the sensitivity of the moisture content measurements in transformer oil dielcometric method in resonant mode. Bulletin of NTU «KhPI», 2014, no.50(1092), pp. 143-149. (Rus).

4. Rudakov V.V., Korobko A.A. The resonance spectra of inhomogeneous coaxial resonators to determine the dielectric constant of liquid media in the microwave band. Bulletin of NTU «KhPI», 2015, no.20(1129), pp. 129-137. (Rus).

5. Rudakov V.V., Korobko A.A. Research of metrological characteristics of transmitters in the form of a step coaxial resonator for dielkometrii inhomogeneous liquid media in the microwave range. Bulletin of $N T U$ «KhPI», 2015, no.51(1160), pp. 91-95. (Rus).

6. Dvoryashin B.V. Osnovyi metrologii $i$ radioizmereniya [Fundamentals of metrology and radio measurements]. Moscow, Radio i svyiz Publ., 1993. 320 p. (Rus).

\section{Received 19.09.2016}

V.V. Rudakov ${ }^{1}$, Doctor of Technical Science, Professor, A.A. Korobko ${ }^{1}$, Postgraduate Student,

${ }^{1}$ National Technical University «Kharkiv Polytechnic Institute», 21, Kyrpychova Str., Kharkiv, 61002, Ukraine.

phone +380936508088, e-mail: andarleks@gmail.com

\section{How to cite this article:}

Rudakov V.V., Korobko A.A. A high sensitive microwave measuring device of the moisture content in the non-polar dielectric liquids based on an inhomogeneous step coaxial resonator. Electrical engineering \& electromechanics, 2016, no.5, pp. 51-56. doi: 10.20998/2074-272X.2016.5.08. 